\title{
Evaluation of EEGs of children referred with first non-febrile seizure in Ahvaz, south west of Iran
}

\author{
Badanie EEG u dzieci przyjętych z powodu pierwszego epizodu drgawek \\ niezwiązanych z gorączką w Ahvaz, w południowo-zachodnim Iranie
}

\author{
Ali Akbar Momen¹, Hannaneh Davoodzadeh²,3, Maryam Morvaridnejad4 \\ ${ }^{1}$ Pediatric Neurologist, Department of Paediatrics, Golestan Hospital, Ahvaz Jundishapur University of Medical Sciences, \\ Ahvaz, Iran \\ ${ }^{2}$ Clinical Research Development Unit, Golestan Hospital, Ahvaz Jundishapur University of Medical Sciences, Ahvaz, Iran \\ ${ }^{3}$ Norman Bethune College of Medicine, Jilin University, Changchun, China \\ ${ }^{4}$ Department of Paediatrics, Golestan Hospital Ahvaz Jundishapur University of Medical Sciences, Ahvaz, Iran
}

Neuropsychiatria i Neuropsychologia 2017; 12, 2: 49-53

Address for correspondence:

Ali Akbar Momen

Ahvaz Jundishapur University of Medical Sciences

Golestan Str. 6135733118 Ahvaz, Iran

e-mail: momen ali@yahoo.com

phone: +989161110400

\begin{abstract}
Introduction: Seizures are one of the most common disorders in children. EEG is the most important tool in diagnosis and follow-up in patients with seizures. To diagnose which children might experience recurring seizures, EEG can be helpful. This research was conducted to investigate risk factors of seizure recurrence in non-febrile seizures.

Methods: In this descriptive study, EEGs were obtained from all children referred to Ahvaz Golestan hospital following an initial, unprovoked, and untreated seizure. Data were analysed by SPSS version 20 , and $P<0.05$ was considered as significant.

Results: Thirty-two children aged 4 months to 14 years participated. The patients mean age was 2.75 years. Eighteen cases $(56.25 \%)$ were male and $14(43.75 \%)$ were female. Twenty-seven of the cases had normal birth weight and five had low birth weight. Of the 32 children evaluated, five children (15.62\%) had developmental retardation status. The average duration of seizures was 155 seconds. A positive family history of seizures was reported in $13(40.62 \%)$ children. EEG findings were abnormal in 19 patients $(59.37 \%)$, and they were normal in 13 patients (40.63\%), in which three forms were seen: focal spikes in 10 patients $(31.25 \%)$, focal spikes with slow waves in six patients (18.75\%), and general spikes with slow waves in three patients $(9.37 \%)$.

Conclusion: This study revealed a significant correlation between the presence of a family history of seizures and developmental delays in children with first non-febrile seizures and abnormal EEG. It is suggested that EEG be conducted on the first non-febrile seizure, especially in children with a positive family history of seizures or developmental delay.
\end{abstract}

Key words: seizures, febrile, electroencephalography, developmental disabilities, child.

\section{Introduction}

Seizures and epilepsy can dominate all aspects of life in affected patients (Baram 2012). Forty per cent of children referred with non-febrile seizures endure recurrent seizures within a sixmonth period, which is mostly seen within the first few weeks after the initial attack (Pellock 1998). Most seizure disorders can be controlled by use of anti-epileptic drugs (Bloechliger $e t$ al. 2015; Löscher et al. 2013), but 10-15\% of all cases are drug-resistant or uncontrolled (Sevilla-Castillo et al. 2009; Pellock 1998). A history of previous symptomatic neurological diseases, focal seizures, symptoms of mental retardation, and abnormal electrical waves in EEG can be helpful in prediction of the likelihood of further recurrent seizures and the decision to begin treatment for the prevention of further seizures (Bodensteiner 2001). Often one of the most important issues in dealing with a child with seizures is obtaining a history, signs of epileptic seizures, and identifying the seizures' foci. The time of the seizure attack, the length of the attack, aura or post ictal phase, a family history of epilepsy and seizure disorders, and history 
of previous convulsive seizures can all assist in dealing with and managing a child with seizure disorders. After obtaining a history and physical examination, diagnostic procedures such as EEG during a seizure or between seizures are useful methods in the evaluation of epileptic attacks (Bodensteiner 2001).

Electroencephalography (EEG), polysomnography, and electroencephalography with computer analysis are the three main diagnostic methods (Laufs 2012; Solomon and Michael 2015). Among these methods, electroencephalography (EEG), because of its ease of use and high performance, is one of the best ways to evaluate epileptic attacks. EEG is a useful and critical tool for seizure evaluation. This device was discovered by Berger in 1929 for the first time (Tudor et al. 2004). The EEG is recorded by electrodes that determine the different electrical potential between two different points in the brain. To record an EEG, 19 electrodes must be placed on symmetric points on the scalp (Tekgul et al. 2005).

Sometimes, rather than physiological waves, pathological waves are detected on the EEG (Gulyás and Freund 2015). Spike waves recorded during seizures on EEGs are the main characteristic and symptom of a neuron convulsion, which can be seen during all seizures and mark a sudden depolarisation attack in a neuron (Hall et al. 2015). If these spike waves that characterize convulsions occur in one point of the brain, a focal epileptic seizure is often seen, but if these waves appear in all of the cerebral cortex, a generalised seizure usually occurs (Pellock 1998, Sevilla-Castillo et al. 2009). During a focal seizure attack, regular slow waves often appear in the same area. During an epileptic attack the waves of that specific type of epilepsy are seen. Each EEG pattern is age-related and differs during sleep and wake cycles, and sometimes it is necessary to compare normal and abnormal EEG waves during sleep and wake cycles. Sometimes EEG patterns represent a certain situation or certain cerebral diseases (Tudor et al. 2004, Pellock 1998). To diagnose which of these children might experience recurring seizures the use of EEG can be a very helpful complementary tool. This study evaluated the EEG of children referred to Ahvaz Golestan Hospital with first non-febrile seizure to investigate the risk factors of seizure recurrence.

\section{Design and method}

The population of this descriptive study consisted of all children referred to the emer- gency ward of Ahvaz Golestan Hospital with a first non-febrile seizure attack and admitted for assessment and treatment to the Paediatric Neurology Subspecialty ward after vital sign stability. After taking history and obtaining physical examination, a form was completed for each patient. Information included in the form were gender, age (by months), place of birth, place of residence, maternal and paternal age and occupation, familial relationship of parents, familial history of epilepsy, and the patients' number of siblings. The participants' birth weight was also included, and less than $2400 \mathrm{gr}$ was considered as low birth weight (Bodensteiner 2001). The form of seizure (tonic, clonic, atonic, myoclonic, tonic-clonic, especially from the viewpoint of non-febrile seizure or another type of seizure classification), diurnal or nocturnal, and the length and the time of the seizure were recorded according to the parents and caregivers of the patients.

Patients were examined and the child's developmental status was determined according to age and Denver Developmental Screening Test II. Then, EEGs were recorded (EEG used with 19-channel set-up and dipole montage) and the results were included in the questionnaire. Data were analysed by SPSS version 20 and $P<0.05$ was considered as significant.

\section{Results}

The age range of the 32 patients studied was between 4 months and 14 years, and the mean age was 2 years and 9 months. Eighteen participants $(56.25 \%)$ were male and $14(43.75 \%)$ were female. The mean paternal age was 34 years with an range of 20 to 45 years. The mean maternal age was 26 years with an age range of 15 to 41 years. The mean duration of seizures was 155 seconds (minimum 30 seconds, maximum 1200 seconds).

All patients resided in the Khuzestan province of Iran, $43.75 \%$ resided in the city of Ahvaz (centre of the province).

Twenty-seven of the cases had normal birth weight and five cases had low birth weight. Of the 32 children evaluated, five children (15.62\%) had developmental retardation and 27 children $(84.37 \%)$ had normal developmental status.

Distribution of EEG findings in patients with the first attack of non-febrile seizures and their results after analysis are shown in Table 1, and 2, respectively. Nineteen patients $(59.37 \%)$ had abnormal EEGs. After analysis of EEGs and abnormal waves the highest pathology rate was 
Table 1. Distribution of EEG findings in patients with the first attack of non-febrile seizures

\begin{tabular}{lcc} 
EEG Findings & Number & Percent \\
Normal & 13 & 40.63 \\
\hline Mildly abnormal & 10 & 31.25 \\
\hline Moderately abnormal & 6 & 18.75 \\
\hline Markedly abnormal & 3 & 9.37 \\
\hline
\end{tabular}

seen in focal spike pattern (10 cases) $(31.25 \%)$ (Table 2).

A positive family history of seizures was reported in $13(40.62 \%)$ children. Distribution of history of seizure disease in relatives of patients with a first febrile seizure attack is shown in Table 3. After analysis of the children's EEGs, 10 of 13 cases with positive family history of seizures had abnormal EEGs, and a statistically significant difference was seen between the history of seizure in first- and second-degree relatives and seizure abnormalities in EEGs $(p=0.04)$.

The most common type of seizure in patients in the present study was generalised tonic-clonic $(43.76 \%)$ (Fig. 1). There was no statistically significant difference between the type of seizure and pathological change in EEG $(p=0.6)$.

\section{Discussion}

Thirty-two children with a first non-febrile seizure attack admitted to Golestan hospital's emergency department were studied.

In Van Donselaar et al.'s study of 84 children referred with first non-febrile seizure, $63.5 \%$ had abnormal EEGs, which is close to the finding of this study (59.37\%) (van Donselaar, 1993).

EEG findings in other studies were as follows: Nypaver et al. study (Nypaver et al. 1992) 64.4\% abnormal, Landfish et al. study (Landfish et al.
Table 2. Distribution of EEG findings after analysis of abnormalities in the patients

\begin{tabular}{|c|c|c|}
\hline $\begin{array}{l}\text { EEG Findings after } \\
\text { analysis }\end{array}$ & Number & Percent \\
\hline Normal & 13 & 40.63 \\
\hline Focal spikes & 10 & 31.25 \\
\hline $\begin{array}{l}\text { Focal spikes and } \\
\text { slow waves }\end{array}$ & 6 & 18.75 \\
\hline $\begin{array}{l}\text { General spikes and } \\
\text { slow waves }\end{array}$ & 3 & 9.37 \\
\hline
\end{tabular}

Table 3. Distribution of history of seizure disease in relatives of patients with a first febrile seizure attack

\begin{tabular}{lcc}
$\begin{array}{l}\text { History of seizure } \\
\text { disorders in relatives }\end{array}$ & Number & Percent \\
\hline First-degree relatives & 6 & 18.75 \\
\hline Second-degree relatives & 5 & 15.62 \\
\hline Third-degree relatives & 2 & 6.25 \\
\hline $\begin{array}{l}\text { Absence of family } \\
\text { history }\end{array}$ & 19 & 59.37 \\
\hline
\end{tabular}

1992) $59.8 \%$ abnormal; Fusun et al. study (Alehan et al. 2001) 55.6\% abnormal, and Udani et al. study (Udani et al. 2009) 63.7\% abnormal EEG. Our findings (59.37\%) were comparable with these findings. However, the Verity study (Verity 1995) and the Udani study (Udani, 2005) showed a lower prevalence of abnormal EEGs compared to our study (respectively, $34.7 \%$ and $45.2 \%$ vs. $59.37 \%$ ). This might be because Golestan Hospital is the only subspecialty paediatric neurology centre in Khuzestan province and the neighbouring provinces, so it covers a large population and is considered as a referral centre for children with seizures, and mostly children with a positive family history or suspicious physical examination are referred for EEGs and follow-up.

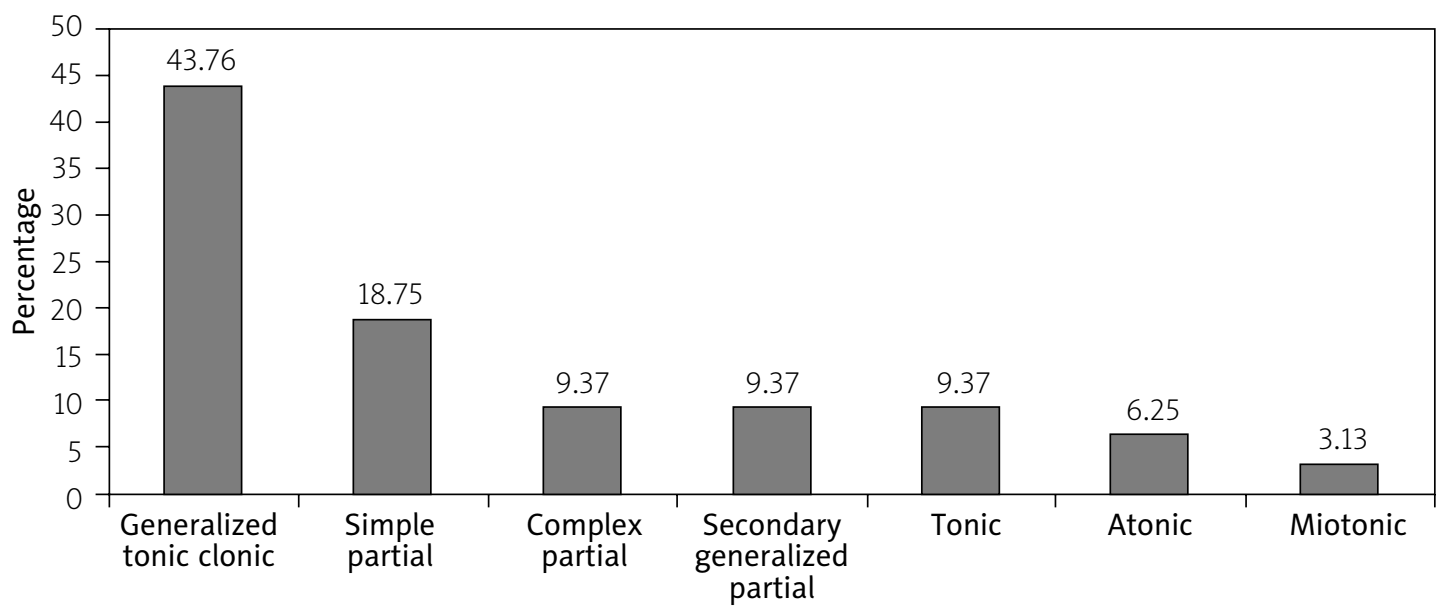

Fig. 1. Prevalence of different type of seizures 


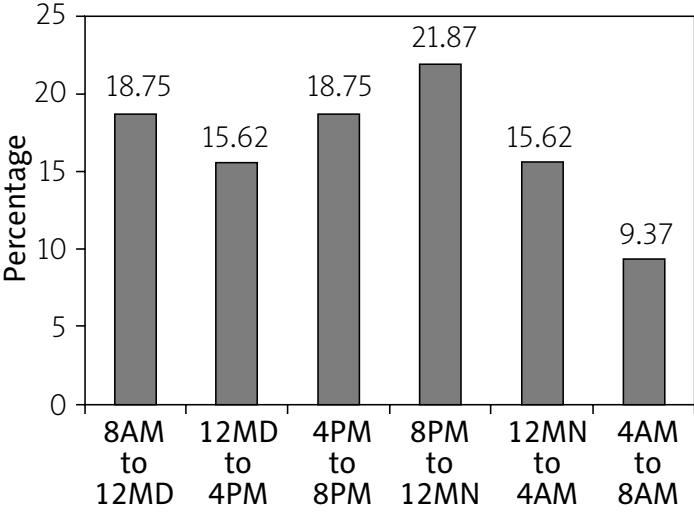

Fig. 2. Distribution of time of seizure occurrence (according to time range in daytime)

Therefore, a higher rate of abnormal EEGs in these children can be expected.

Another risk factor for non-febrile seizures is a positive family history. History of seizure in the family, especially in first-degree relatives, is important in unexplained epilepsy. In our study $40.63 \%$ of the children had a positive familial history in first-, second-, and third-degree relatives, whereas in Verity's study (Verity 1995) only $24.7 \%$ had a positive family history and in Chowdary et al.'s study (Chowdary et al. 2004) $28.3 \%$ had a positive family history. The high prevalence of positive family history in this study may be because of interfamily marriages and potential genetic syndromes in children.

Another important risk factor is the child's developmental status, which showed a statistically significant relationship with abnormal EEGs in our study. In this study $15.63 \%$ of the children had developmental delays, in comparison to $12.21 \%$ and $15.30 \%$ of the children in Verity's study (Verity 1995) and Chowdary et al. study (Chowdary et al. 2004), respectively.

In all studies, generalised tonic-clonic seizure was the most common type of seizure, which was similar to the results of our study (43.7\%). (Udani 2005; Verity 1995; Udani et al. 2009; Alehan et al. 2001; Landfish et al. 1992; Nypaver et al. 1992, van Donselaar 1993).

Also, the highest abnormality that was seen in EEGs in all studies was the focal spike pattern, which was comparable with our study (30.25\% of $59.37 \%$ abnormal EEGs). Just in Munot et al.'s study (Udani et al. 2009) the most common abnormality was focal spike and slow waves (respectively, $38.4 \%$ of $63.7 \%$ abnormal EEGs), which may be because of the difference of the study population's age (from birth to three years old $v$ s. from 4 months to 14 years old in our study and other studies).
In two studies (Udani 2005; Alehan et al. 2001) prospective follow-up studies were done for two years and one year, respectively. Both studies reached the conclusion that there is a very close relationship between EEG abnormality and recurrent seizures in the future $(p<0.01)$.

A limitation of our study was in data collection, due to low educational levels and non-cooperation of the patients' parents. Also, our study was conducted over a one-year period with a small population. Conducting long-term and prospective studies to assess the incidence of recurrent seizures after first seizure in children with normal EEGs, and comparison to children with abnormal EEGs, is recommended in order to assess drug therapy requirements for seizure control and to decrease the complications.

\section{Conclusions}

A significant relationship was seen between familial history of seizures and delayed developmental changes with abnormal EEG changes. It is suggested that an EEG is performed in the first non-febrile seizure, especially in children with a positive family history of seizure or developmental delay.

\section{Acknowledgements}

The authors hereby express their gratitude to Ahvaz Jundishapur University of Medical Sciences for their support, and to all of the colleagues who participated in this research. They also thank the Clinical Research Development Unit of Golestan Hospital of Ahvaz.

\section{References}

1. Alehan FK, Morton LD, Pellock JM. Utility of electroencephalography in the pediatric emergency department. J Child Neurol 2001; 16: 484-487.

2. Baram TZ. The brain, seizures and epilepsy throughout life: understanding a moving target. Epilepsy Curr 2012; 12: 7-12.

3. Bloechliger M, Rüegg S, Jick SS, et al. Antipsychotic Drug Use and the Risk of Seizures: Follow-up Study with a Nested Case-Control Analysis. CNS Drugs 2015; 29: 591-603.

4. Bodensteiner JB. Predictors of Multiple Seizures in a Cohort of Children Prospectively Foilowed from the Time of Their First Unprovoked Seizure. Clin Pediatr (Philia) 2001; 40: 122-123.

5. Chowdary G, Murthy J, Vijay S. Prevalence of seizure disorders associated with neurocysticercosis: a community based study - Comprehensive Rural Epilepsy Study South India (CRESSI) Presented at Asian and Oceanic congress of Neurology. The Asian and Oceanic Congress of Neurology; Singapore 2004.

6. Gulyás Al, Freund TT. Generation of physiological and pathological high frequency oscillations: the role of periso- 
matic inhibition in sharp-wave ripple and interictal spike generation. Curr Opin Neurobiol 2015; 31: 26-32.

7. Hall S, Hunt M, Simon A, et al. Unbalanced Peptidergic Inhibition in Superficial Neocortex Underlies Spike and Wave Seizure Activity. J Neurosci 2015; 35: 9302-9314.

8. Landfish N, Gieron-Korthals M, Weibley RE, Panzarino V. New onset childhood seizures. Emergency department experience. J Fla Med Assoc 1992; 79: 697-700.

9. Laufs H. Functional imaging of seizures and epilepsy: evolution from zones to networks. Curr Opin Neurol 2012; 25: 194-200.

10. Löscher W, Klitgaard H, Twyman RE, Schmidt D. New avenues for anti-epileptic drug discovery and development. Nature Reviews Drug Discovery 2013; 12: 757-776.

11. Nypaver MM, Reynolds SL, Tanz RR, Davis AT. Emergency department laboratory evaluation of children with seizures: Dogma or dilemma? Pediatr Emerg Care 1992; 8: 13-16.

12. Pellock JM. Treatment of seizures and epilepsy in children and adolescents. Neurology 1998; 51: S8-S14.

13. Sevilla-Castillo R, Palacios G, Ramirez-Campos J, et al. Methylprednisolone for the treatment of children with refractory epilepsy. Neuropediatrics 2009; 40: 265-268.

14. Solomon T, Michael B. Encephalitis, seizures and epilepsy: diagnostic challenges and clinical management. J Neurol Sci 2015; 357: e459.

15. Tekgul H, Bourgeois BF, Gauvreau K, Bergin AM. Electroencephalography in neonatal seizures: comparison of a reduced and a full 10/20 montage. Pediatr Neurol 2005; 32: 155-161.

16. Tudor M, Tudor L, Tudor KI. [Hans Berger (1873-1941) - the history of electroencephalography]. Acta Medica Croatica: Casopis Hravatske Akademije Medicinskih Znanosti 2004; 59: 307-313.

17. Udani V. Pediatric epilepsy - an Indian perspective. Indian J Pediatr 2005; 72: 309-313.

18. Udani V, Munot P, Ursekar M, Gupta S. Neonatal hypoglycemic brain-injury a common cause of infantile onset remote symptomatic epilepsy. Indian Pediatr 2009; 46: 127-132.

19. Van Donselaar C. Reliability of the diagnosis of a first seizure. Clin Neurol Neurosurg 1993; 95: 163.

20. Verity CM. The place of the EEG and imaging in the management of seizures. Arch Dis Child 1995; 73: 557-562. 